(c) American Dairy Science Association, 2003.

\title{
Short Communication: Effects of Subacute Ruminal Acidosis on Free-Choice Intake of Sodium Bicarbonate in Lactating Dairy Cows
}

\author{
J. E. Keunen ${ }^{\star, 1}$, J. C. Plaizier†, I. Kyriazakisł, T. F. Duffield ${ }^{\star, 2}$, T. M. Widowski, \\ M. I. Lindinger ${ }^{\star, 3}$, and B. W. McBride*,1 \\ *University of Guelph, Guelph, ON, N1G 2W1, Canada, \\ †Department of Animal Science, University of Manitoba, \\ Winnipeg, MB, R3T 2N2, Canada \\ $\ddagger$ Animal Nutrition and Health Department, Scottish Agricultural College, \\ King's Buildings, West Mains Road, Edinburgh, EH9 3JG, UK
}

\section{ABSTRACT}

The effect of inducing subacute ruminal acidosis (SARA) on the free-choice intake of sodium bicarbonate (SB) was investigated in four midlactation Holstein cows in a switchover experiment with four 1 -wk periods. The SARA was induced by replacing $25 \%$ of the ad libitum intake of total mixed ration (TMR) with pellets containing 50\% ground wheat and 50\% ground barley and restricting access to TMR from 0700 to $1700 \mathrm{~h}$. Control consisted of feeding TMR ad libitum. Powdered SB was provided for ad libitum consumption. Rumen $\mathrm{pH}$ was measured continuously using indwelling $\mathrm{pH}$ probes. Induction of SARA reduced $(P<0.05)$ the average daily rumen $\mathrm{pH}$ from 6.08 to 5.87 , increased $(P<$ $0.05)$ the average duration of rumen $\mathrm{pH}$ below 6 from $547 \mathrm{~min} \cdot \mathrm{d}^{-1}$ to $916 \mathrm{~min} \cdot \mathrm{d}^{-1}$, and increased $(P<0.05)$ the average duration of rumen $\mathrm{pH}$ below 5.6 from 132 $\mathrm{min} \cdot \mathrm{d}^{-1}$ to $397 \mathrm{~min} \cdot \mathrm{d}^{-1}(P<0.05)$ but did not significantly affect SB intake. Average intake of SB was 26.8 $\mathrm{g} \cdot \mathrm{d}^{-1}$ during SARA and $34.5 \mathrm{~g} \cdot \mathrm{d}^{-1}$ during control. These low SB intakes must not have substantially affected rumen $\mathrm{pH}$. Sodium bicarbonate intake differed significantly $(P<0.05)$ between cows. These data indicate that cows did not select SB in order to attenuate SARA. (Key words: subacute ruminal acidosis, sodium bicarbonate, feed intake, dairy cow)

Abbreviation key: SARA = subacute ruminal acidosis, $\mathbf{S B}=$ sodium bicarbonate.

Received August 1, 2002.

Accepted September 20, 2002.

Corresponding author: B. W. McBride; email: bmcbride@ uoguelph.ca.

${ }^{1}$ Department of Animal and Poultry Science.

${ }^{2}$ Department of Population Medicine, OVC.

${ }^{3}$ Department of Human Biology and Nutrition.

Subacute ruminal acidosis (SARA) is a common and economically important metabolic disorder of dairy cattle (Nocek, 1997; Garret et al., 1999). Due to the difficulty in diagnosing SARA, limited information on the incidence of this disorder exists (Garret et al., 1999). However, Oetzel et al. (1999) found an incidence of SARA of $20.1 \%$ in cows between 1 and 120 DIM on commercial dairy farms in Wisconsin. The SARA commonly occurs in early lactation dairy cows when the rumen has not yet adapted from a switch from a foragebased to a concentrate-based diet (Burrin and Britton, 1986; Britton and Stock, 1987). Fermentation of nonstructural carbohydrates, such as starches and sugars, leads to production of large quantities of VFA and lactate that can accumulate in the rumen and subsequently decrease rumen $\mathrm{pH}$ (Briggs et al., 1957; Rumsey et al., 1970).

Sodium bicarbonate (SB) is a weak base that buffers hydrogen ions of organic acids (Ha et al., 1983). Dietary $\mathrm{SB}$ increases rumen $\mathrm{pH}$ and prevents rumen epithelium damage and ruminal stasis that often accompanies SARA (Kezar and Church, 1979). Studies involving SB in the diet of dairy cows have shown varying degrees of success in maintaining or increasing feed intake (Erdman, 1988).

Induction of SARA in lactating dairy cows increases the preference of long alfalfa hay over pelleted alfalfa (Keunen et al., 2002). As intake of long hay will result in more saliva production and rumen buffering than intake of pelleted alfalfa, this indicates that cows select feeds with high rumen buffering capacity in an attempt to prevent SARA. It has been proposed that ruminants increase their intake of SB in order to prevent low rumen $\mathrm{pH}$. Cooper et al. (1995) suggested that ruminants will alter diet selection to attempt to correct manipulated decreases in rumen $\mathrm{pH}$ and increases in rumen osmolality. However, other studies have shown varying degrees of preference for SB (Cooper et al., 1996; Phy 
and Provenza, 1998a,b; James and Kyriazakis, 1999; Cumby et al., 2001). Of these, only Cumby et al. (2001) have done work involving SARA and dairy cows, using a pelleted form of SB. Anecdotal accounts suggest that cattle and sheep fed high-grain diets will readily consume powdered SB offered free choice (Phy and Provenza, 1998a). To date, to the best of our knowledge, no studies have been performed that have given the dairy cow ad libitum access to powdered SB during bouts of SARA. Given the results of Cooper et al. (1995) and Phy and Provenza (1998a,b), we hypothesized that inducing SARA in dairy cows would increase their intake of powdered SB offered free choice.

Four multiparous, ruminally fistulated Holstein dairy cows were housed in individual tie stalls at the Elora Dairy Research Centre in accordance with the guidelines of the Canadian Council of Animal Care. Cows averaged $691 \pm 86 \mathrm{~kg}$ of BW and $175 \pm 57 \mathrm{DIM}$ at the beginning of the experiment. Average milk yield at the start of the experiment was $31 \pm 6.7 \mathrm{~kg} \cdot \mathrm{d}^{-1}$. The experiment was conducted as a switchover design with four periods of $1 \mathrm{wk}$. During each period, SARA was induced in two cows according to the protocol described by Keunen et al. (2002). The other two cows received a TMR for ad libitum intake (control). Each subsequent week treatments were switched. The SARA was induced by replacing $25 \%$ of the TMR DMI measured in the previous period with an equal amount of DM from grain pellets (50\% wheat:50\% barley) and restricting the availability of TMR between 0700 and $1700 \mathrm{~h}$ (Keunen et al., 2002).

Cows received a TMR that did not contain SB and had ad libitum access to fresh water. The TMR consisted of (as-fed basis) $46.0 \%$ corn silage, $16.5 \%$ high moisture corn, $19.0 \%$ mixed haylage, $5.0 \%$ mixed hay, and $13.5 \%$ lactating cow supplement. The lactating cow supplement contained (as-fed basis), 28.2\% soybean hulls, $5.7 \%$ blood meal, $7.3 \%$ corn gluten meal, $11.5 \%$ soybean meal, $2.65 \%$ dicalcium phosphate, $3.2 \%$ calcium carbonate, $0.6 \%$ magnesium oxide, $1.7 \%$ salt, $1.3 \%$ Dynamate $(22 \% \mathrm{~S}, 18 \% \mathrm{~K}, 11 \% \mathrm{Mg}$, IMC Feed Ingredients, Lake Forest, IL), 0.4\% Dairyman's Edge (Yeast, LBJ Pakke Inc., Waddington, NY), 0.3\% FFM Micro premix (dicalcium phosphate, calcium carbonate, magnesium oxide, trace minerals, vitamin A, vitamin D, vitamin E, Floradale Feedmill, Floradale, ON), 8.6\% wheat shorts, $2.9 \%$ fish meal, 3.6\% molasses, $0.2 \%$ Alimet (DL-Methionine Hydroxy Analogue, Novus, St. Louis, MO) 7.2\% wheat grain, and $14.3 \%$ roasted soybeans. Feed intakes were determined daily and representative feed and orts samples were taken each day. The TMR samples were pooled by week and orts samples were pooled by weight for cow and week. The DM content of these samples were determined by drying in a $60^{\circ} \mathrm{C}$ oven for $48 \mathrm{~h}$
(AOAC, 1990). The TMR samples were also analyzed for CP using the macro-Kjeldahl procedure (AOAC, 1990), ADF (AOAC, 1990), and NDF (Goering and Van Soest, 1970). Milk yields were recorded daily throughout the entire experiment.

Rumen $\mathrm{pH}$ was monitored continuously via in-dwelling $\mathrm{pH}$ probes using the method described by Cumby et al. (2001). Rumen pH was measured every second, but only average values over $60 \mathrm{~s}$ were stored and used for subsequent analysis. These data were summarized by calculating average $\mathrm{pH}$, time below $\mathrm{pH} 6$, and time below $\mathrm{pH} 5.6$ area (time $\times \mathrm{pH}$ below $\mathrm{pH} 6$ and area below pH 5.6) for each 24-h period.

Each cow had its own 7.5-L bucket filled with SB (Arm \& Hammer feed grade, Church and Dwight Co., Inc.) attached to a partition on one side of the feed manger throughout the experiment. The side of the manger that held the bucket was randomized before the start of the experiment to remove bias as to side of preference. In the week before the experiment, cows were allowed access to their bucket filled with SB so that animals were familiar with the bucket and its contents and to ensure that cows could readily access the SB. Spillage of SB was minimized by filling not more than the bottom $20 \%$ of the bucket with SB. During the experiment, cows had continuous access to the SB except for $1 \mathrm{~h} \cdot \mathrm{d}^{-1}$ (0900 to $1000 \mathrm{~h}$ ), where SB intake was determined for each cow. Each day cows received $600 \mathrm{~g}$ of fresh, dry SB in their bucket between 0900 and $1000 \mathrm{~h}$. The following day, each bucket was removed and daily intake of SB was determined, with the remaining sample of SB put in a $60^{\circ} \mathrm{C}$ oven for $48 \mathrm{~h}$ to determine the DM. Daily DM intake of the SB was determined by subtracting the remaining dry SB from the initial known amount of SB (i.e., $600 \mathrm{~g}$ ) at $100 \%$ DM.

Analysis of variance of weekly averages of $\mathrm{pH}$ data, SB intakes, DMI, and milk yields for each cow was conducted using the general linear models procedure (SAS, 1990) using a model for a crossover design with cow, diet, and week as fixed effects. A probability level of less than 0.05 was considered significant.

The TMR hay had a composition of (DM basis) $50.4 \%$ $\mathrm{DM}, 15.4 \% \mathrm{CP}, 36.2 \% \mathrm{NDF}$, and $23.6 \% \mathrm{ADF}$. The wheat and barley pellet had a composition of (DM basis) $87.3 \%$ $\mathrm{DM}, 12.5 \% \mathrm{CP}, 16.4 \% \mathrm{NDF}$, and $4.2 \% \mathrm{ADF}$.

Induction of SARA resulted in a significant drop $(P$ $<0.05$ ) in average daily rumen $\mathrm{pH}$ of 0.22 units (Table 1) and increased the duration of time with rumen $\mathrm{pH}$ below 6.0 from $547 \pm 63.4 \mathrm{~min}$ to $915.7 \pm 63.4 \mathrm{~min}$. Duration of time with rumen $\mathrm{pH}$ below 5.6 was also increased from $131.9 \pm 36.1 \mathrm{~min}$ to $397.0 \pm 36.1 \mathrm{~min}$. Cows on the SARA model also had a significantly greater area $\left(\min \times \mathrm{pH} \cdot \mathrm{d}^{-1}\right)$ below $\mathrm{pH} 6(353.0 \pm 31.9$ vs. $151.8 \pm 31.9)$ and below pH $5.6(86.2 \pm 12.5$ vs. 30.3 
Table 1. Summary of DMI and daily averages of continuous $\mathrm{pH}$ data by treatment.

\begin{tabular}{|c|c|c|c|}
\hline & SARA $^{1}$ & Control & $\mathrm{SE}$ \\
\hline $\mathrm{DMI}, \mathrm{kg} \cdot \mathrm{d}^{-1}$ & 21.0 & 20.2 & 0.4 \\
\hline Average $\mathrm{SB}^{2}$ intake, $\mathrm{g} \cdot \mathrm{d}^{-1}$ & 26.8 & 34.5 & 3.6 \\
\hline Average $\mathrm{pH}$ & $5.86^{\mathrm{a}}$ & $6.08^{\mathrm{b}}$ & 0.04 \\
\hline Time $<\mathrm{pH} 6.0, \mathrm{~min} \cdot \mathrm{d}^{-1}$ & $915.7^{\mathrm{a}}$ & $546.9^{\mathrm{b}}$ & 63.4 \\
\hline Area $<\mathrm{pH} 6.0, \min \times \mathrm{pH} \cdot \mathrm{d}^{-1}$ & $353.0^{\mathrm{w}}$ & $151.8^{\mathrm{x}}$ & 31.9 \\
\hline Time $<\mathrm{pH} 5.6, \mathrm{~min} \cdot \mathrm{d}^{-1}$ & $397.0^{\mathrm{w}}$ & $131.9^{x}$ & 36.1 \\
\hline Area $<\mathrm{pH} 5.6, \min \times \mathrm{pH} \cdot \mathrm{d}^{-1}$ & $86.2^{\mathrm{a}}$ & $30.3^{\mathrm{b}}$ & 12.5 \\
\hline
\end{tabular}

$\pm 12.5)$ than the cows on the control treatment $(P<0.05)$. Rumen $\mathrm{pH}$ during SARA was similar to that observed in transition dairy cows in the first week postcalving by Plaizier et al. (1999) and that observed in cows experiencing SARA by Cumby et al. (2001) and Keunen et al. (2002). SARA did not significantly affect milk yields. These yields averaged $30.4 \pm 0.5 \mathrm{~kg} \cdot \mathrm{d}^{-1}$ (mean $\pm \mathrm{SE}$ ) during SARA and $29.5 \pm 0.5 \mathrm{~kg} \cdot \mathrm{d}^{-1}$ during control. Inducing SARA also did not significantly affect DMI. Dry matter intake was on average $21.0 \pm 0.5 \mathrm{~kg} \cdot \mathrm{d}^{-1}$ during SARA and $20.2 \pm 0.5 \mathrm{~kg} \cdot \mathrm{d}^{-1}$ during control periods (Table 1). Individual cow intakes of SB were highly variable and independent of treatment. SB intake was significantly $(P<0.05)$ different between cows, but inducing SARA did not significantly $(P=0.17)$ affect SB intake (Table 1). Intakes of SB averaged $34.5 \pm 3.6 \mathrm{~g} \cdot \mathrm{d}^{-1}$ for Control treatment periods and $26.8 \pm 3.6 \mathrm{~g} \cdot \mathrm{d}^{-1}$ for SARA periods (Table 1).

In the present study, SB was removed from the TMR and the free-choice intake of powdered SB appeared to be too low to provide sufficient rumen buffering and affect rumen $\mathrm{pH}$ (NRC, 2001). It is recommended that lactating dairy cows receive 0.6 to $0.8 \%$ of DMI buffer (SB) in their diet $\left(\sim 200 \mathrm{~g} \cdot \mathrm{d}^{-1}\right)(\mathrm{NRC}, 2001)$. Only on 1 $d$ during the entire experiment did one cow have a SB intake level (206 g) that would meet the recommended level of SB in the diet $(0.9 \%$ SB of their DMI).

The nutritional model used to induce SARA in his study was also used by Plaizier et al. (2001), Keunen et al. (2002), and Krajcarski-Hunt et al. (2002). This induction of SARA reduced DM and NDF digestibility (Plaizier et al., 2001; Krajcarski-Hunt et al., 2002) and increased the preference for long alfalfa hay compared with pelleted alfalfa (Keunen et al., 2002). Hence, this level of SARA elicited animal responses.

Phy and Provenza (1998a) found that after feeding rolled barley, lambs preferred pellets with SB (2\% asfed basis) to pellets with sodium chloride and that following the consumption of a high-wheat diet, lambs increased their intake of SB in solution (2\%). Phy and
Provenza (1998b) showed that intake of SB was effective in attenuating depressed feed intake associated with excessive consumption of rolled barley. Although rumen conditions were not measured in these studies, their findings suggest that a reduction of rumen $\mathrm{pH}$ increases the preference for SB.

Cooper et al. (1996) showed that inclusion of SB into high-energy density increased the feed intake of sheep. However, James and Kyriazakis (1999) observed that inclusion of $4 \%$ SB had no effect on diet selection in sheep offered a low- or a high-energy density feed. Cumby et al. (2001) induced SARA and gave cows the choice between pelleted feeds that contained either $4 \%$ $\mathrm{SB}$ or $4.5 \% \mathrm{NaCl}$. Cows preferred SB pellets over salt pellets and consumed on average $298 \mathrm{~g} \cdot \mathrm{d}^{-1}$ of SB through the pellets. However, SB preference might have been due to aversion to the salt pellets, as after the removal of salt from the control pellets, cows preferred control pellets to SB pellets (J. L. Cumby, J. C. Plaizier, I. Kyriazakis, and B. W. McBride, unpublished observations). This would suggest adverse organoleptic properties of SB.

In the current study, the intake of SB was not sufficient enough in magnitude or duration to sufficiently impact the rumen $\mathrm{pH}$ and affect diet selection. Therefore, inadequate positive reinforcement would be present for the cows to select SB again and overcome the adverse organoleptic properties of the SB. Lack of SB preference was likely not due to insufficient rumen $\mathrm{pH}$ depression, as similar $\mathrm{pH}$ depression affected diet choice in previous studies.

\section{REFERENCES}

Association of Official Analytical Chemists. 1990. Official Methods of Analysis. (15th ed.) AOAC, Arlington, VA.

Briggs, P. K., J. D. Hogan, and R. L. Reed. 1957. The effect of volatile fatty acids, lactic acid and ammonia on rumen $\mathrm{pH}$ in sheep. Aust. J. Agric. Res. 8:674-682.

Burrin, D. G., and R. A. Britton. 1986. Response to monensin in cattle during subacute acidosis. J. Anim. Sci. 63:888-893. 
Britton, R. A., and R. A. Stock. 1987. Acidosis, rate of starch digestion and intake. Pages 125-137 in Proc. 1986 Feed Intake Symposium. Norman, OK.

Cooper, S. B. D., I. Kyriazakis, and J. D. Oldham. 1996. The effects of physical form of feed, carbohydrate source, and inclusion of sodium bicarbonate on the diet selections of sheep. J. Anim. Sci. $74: 1240-1251$

Cooper, S. B. D., I. Kyriazakis, and J. V. Nolan. 1995. Diet selection in sheep: the role of the rumen environment in the selection of a diet from two feeds that differ in their energy density. Br. J. Nutr. 74:39-54.

Cumby, J. L., J. C. Plaizier, I. Kyriazakis, and B. W. McBride. 2001. Effect of subacute ruminal acidosis on the preference of cows for pellets containing sodium bicarbonate. Can. J. Anim. Sci. 81:149-152.

Erdman, R. A. 1988. Dietary buffering requirements of the lactating dairy cow: a review. J. Dairy Sci. 71:3246-3266.

Garrett, E. F., M. N. Pereira, K. V. Norlund, L. E. Armentano, W. J. Goodger, and G. R. Oetzel. 1999. Diagnostic methods for the detection of subacute ruminal acidosis in dairy cows. J. Dairy Sci. 82:1170-1178.

Goering, H. K., and P. J. Van Soest. 1970. Forage Fiber Analysis (Apparatus, Reagents, Procedures, and Some Applications). Agric. Handbook No. 379. ARS-USDA, Washington, D.C.

Ha, J. K., R. J. Emerick, and L. B. Embry. 1983. In vitro effect of pH variations on rumen fermentation, and in vivo effects of buffers in lambs before and after adaptation to high concentrate diets. J. Anim. Sci. 56:698-706.

James, S. M., and I. Kyriazakis. 1999. The effect of consumption of foods that differ in energy density and/or sodium bicarbonate supplementation on subsequent diet selection in sheep. Page 114 in Proc. 115th Mtg. Br. Soc. Anim. Sci.
Keunen, J. E., J. C. Plaizier, I Kyriazakis, T. F. Duffield, T. M. Widowski, M. I. Lindinger, and B. W. McBride. Effects of a subacute ruminal acidosis model on the diet selection of dairy cows. J. Dairy Sci. 85:3304-3313.

Kezar, W. W., and D. C. Church. 1979. Effect of thiopeptin and sodium bicarbonate on the prevention of lactic acidosis induced in sheep. J. Anim. Sci. 49:1396-1402.

Krajcarski-Hunt, H., J. C. Plaizier, J. P. Walton, R. Spratt, and B. W. McBride. 2002. Effect of subacute ruminal acidosis on in situ fiber digestion in lactating dairy cows. J. Dairy Sci. 85:570-573.

National Research Council. 2001. Nutrient requirements for dairy cattle. Natl. Acad. Sci. Washington, DC.

Nocek, J. E. 1997. Bovine acidosis: implications on laminitis. J. Dairy Sci. 80:1005-1028.

Oetzel, G. R., K. V. Norlund, and E. F. Garrett. 1999. Effect of ruminal $\mathrm{pH}$ and stage of lactation on ruminal lactate concentrations in dairy cows. J. Dairy Sci. 82(Suppl. 1):38.

Phy, T. S., and F. D. Provenza. 1998a. Sheep fed grain prefer foods and solutions that attenuate acidosis. J. Anim. Sci. 76:954-960.

Phy, T. S., and F. D. Provenza. 1998b. Eating barley too frequently or in excess decreases lambs' preference for barley but sodium bicarbonate and lasalocid attenuate the response. J. Anim. Sci. 76:1578-1583.

Plaizier, J. C., A. Martin, T. Duffield, R. Bagg, P. Dick, and B. W. McBride. 1999. Monitoring acidosis in the transition dairy cow. J. Dairy Sci. 82(Suppl. 1):110.

Plaizier, J. C., J. E. Keunen, J. P. Walton, T. F. Duffield, and B. W. McBride. 2001. Effect of subacute ruminal acidosis on in situ digestion of mixed hay in lactating dairy cows. Can. J. Anim. Sci. 81:421-423.

Rumsey, T. S., P. A. Putnam, J. Bond, and R. R. Oltjen. 1970. Influence of level and type of diet on ruminal $\mathrm{pH}$ and VFA respiratory rate and EKG patterns of steers. J. Anim. Sci. 31:608-616.

SAS. 1990. SAS User's Guide: Statistics. SAS Institute, Cary, NC. 